\title{
Exploration on Design Methods of Fire Extinguishers Based on the Level of Demand
}

\author{
Hu Wenfei \\ Wenzhou Vocational \& Technical College, Wenzhou. 325035 \\ 61230934@qq.com
}

Keywords: fire extinguisher; design; application

\begin{abstract}
According to the statistics of the National Bureau of Statistics, the number of fires in China has been increasing progressively year after year and it is more than 125,000 each year on average; thereinto, 152,157 fires occurred in 2012, with 1028 deaths and direct economic losses of 2.177 billion yuan. According to the data shown by the National Fire Protection Administration, the fire that has been caused by the failure of effective control at the beginning of the fire because there is no fire extinguisher in the household accounts for a large proportion of about $30.7 \%$. In an organization's fire prevention investigation, it was found that there was no standing fire-fighting equipment in nearly $90 \%$ of the residents' homes or the fire extinguishers in the community failed to achieve the desired effect; most of them refused to prepare because they were dissatisfied with the existing fire extinguishers. Today, when the fire is much fiercer than the tiger, it is imperative to design a fire extinguisher that the public is willing to accept. The design of a creative fire extinguisher is to give the public a new impression and use experience, increase the residents' acceptance to the standing fire extinguisher, and meet the requirements of the modernization construction of China and the market demand of today's society.
\end{abstract}

\section{Introduction}

\subsection{Existing fire extinguisher products in the market}

There are many types of fire extinguishers in the market. According to their movement methods, they can be divided into portable type and trolley type, and they can be divided into gas cylinder type, pressure storage type and chemical reaction type according to power source of fire extinguishing agent, while it can be further divided into foam type, dry powder type, halo alkane type, carbon dioxide type, and clean water type, etc. according to the fire extinguishing agent filled inside.

\subsection{Analysis on the existing fire extinguisher products}

The above fire extinguishers include most of the fire extinguishers in the market. It is not difficult to find through research that there are many kinds of fire extinguishers available in the market, but they are too single in terms of the usage mode. They are all operated with one hand carrying the device or the trolley and the other hand carrying the shower nozzle (see Figure 1). In terms of consumer experience, the appearance of these fire extinguishers is extremely similar, and it is easy to cause aesthetic fatigue; besides, it will result in fatigue to operate with one hand and the appearance is not beautiful enough. In general, it is difficult to make people generate a sense of closeness, let alone the preparation and use. 

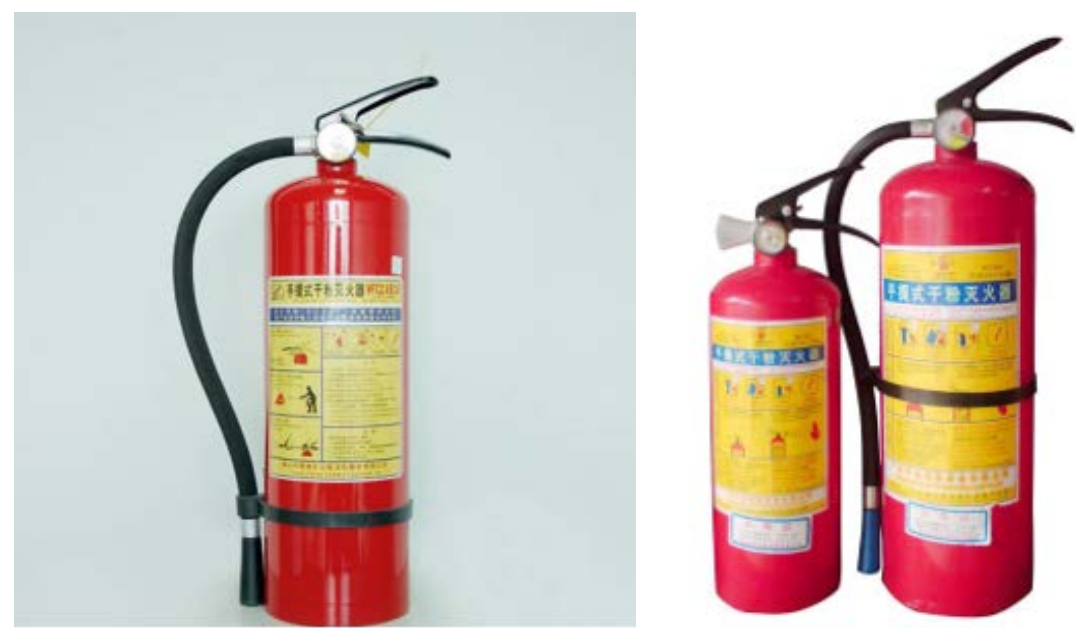

Figure 1: The existing fire extinguishers in the market are too singular

\section{Target population}

The target population in this investigation and survey is the main body of today's society: post-70s and 80s. These people are between the ages of 25 and 45 years old. According to the regulations of relevant departments of our country, this group belongs to the young and middle-aged people of the society, who are an important part of the family, bear the main responsibility in the social and family life, and are the main consumers of fire extinguishers.

The target population is the social subject group, the post-70s and 80s, in the current stage.

According to the subjective perspective of the target group: all people have the instinct of life and death according to the theory of human body composition and they are constantly fighting for the things they pursue all the life. From the psychological point of view, every thing that people get through hard work is endowed with an emotionally unique brand and value. Young and middle-aged people are at the golden stage of their lives, who are motivated and eager to get something nice through their own efforts. Then, in the event of a fire, the young and middle-aged members of the society will respond positively, act quickly in the early stages of the fire, and try to retain all the items that they have obtained through their efforts. People will try their best to rescue what they have got through hard work; even if it is a tiny little bit, they will not give it up. In addition, young and middle-aged people are at the peak of their lives and are confident in themselves. Even in the face of fire, they will show their excellent qualities and are willing to solve problems through their own treatment.

According to the objective analysis on the target group: 1. The brain function of the young and middle-aged people has matured and the body system function has peaked, who are rich in creative and dialectical thinking. This group is willing to accept new things due to the influence of the times; 2. The personality of them has been perfected, stable and mature. They are full of hope for the future, and meanwhile pay more attention to the current behaviors, who are full of rational thinking and a small amount of perceptual definition about the corresponding things. 3. Their fantasy and curiosity about fresh things have been moderately reduced; although they are still interested in fresh things, they begin to keep vigilant and in general, they have a great passion for life; 4 . In terms of other psychological aspects, young and middle-aged people are the current subject of society, who are rich in positive energy and honest to people, hope to be trusted and are willing to believe in others; 5. The body function of them has peaked in life, and the physical strength has reached a peak, who can face all problems in social life. 


\section{Theoretical basis and design analysis}

\subsection{Theoretical basis}

\subsubsection{Ergonomics}

Product modeling is the core of product design, and it has certain aesthetic laws such as unity and change, contrast and coordination, rhythm and rhyme, gradual change and transition, proportion and scale, stability and lightness. In the modeling design stage, each aspect of the modeling shall be designed like the function, construction and ergonomics, etc. When the modeling is considered, the function and construction cannot be ignored. Product function and construction will usually affect product modeling directly, but sometimes, in order to create new modeling, the function and construction must be changed. However, at this time, we cannot ignore the existence of factors such as production methods, materials, and production costs, or emphasize the modeling blindly. Therefore, it is required to repeatedly think over technologies and seek the most suitable conditions for design.

The development of modern science and technology makes the relationship between people and the machines they operate more and more close. The so-called ergonomic point of view simply means taking the movements and visual characteristics of human beings into consideration, and seeking for reconciliation between products and people psychologically, perceptually and physically, which is an indispensable technology for users to use convenient products.

The operating form and operating system of the entire fire extinguisher must conform to ergonomics and follow the following basic principles:

1) The principle of rationality, that is, ensure the rationality and clarity on the basis of system design. Both qualitative and quantitative analysis should be conducted for any design so as to strive to reduce irrational factors, and base it on quantitative optimization and improvement. Design should not follow the herd, which must be based on correct and systematic facts and data to conduct rigorous theoretical analysis and convince people by reasoning and emotions.

2) The principle of dynamics, that is, have the concept of operation in four-dimensional space or five-dimensional space. A piece of works not only is a two-dimensional plane or three-dimensional stereo, but also has a multi-dimensional factor such as the transformation of time and space, and the evolution of emotion and thinking.

3) The principle of diversification, that is, the diversified consideration of design factors. At present, the appearance of more and more professional investigators and companies has brought rich materials and evidence for design. However, how to obtain effective information and analyze design information is actually a process system with creative thinking and methods.

4) The principle of interaction, that is, the interface design emphasizes the interaction process. On the one hand, it is the information transmission of things; on the other hand, it is the acceptance and feedback of people, and the information of any object can be actively recognized and grasped.

5) The principle of commonality, that is, grasp the coordination and unification of three types of interfaces. The functions, emotions and environment cannot exist in isolation, but should complement each other to form a vital circulatory system. Only in this way, a design is an excellent design with powerful life.

\subsubsection{Product color}

The purpose of color design of industrial products is to make the products have a perfect modeling effect, so that the material function and use environment of products will generate an unified and coordinated feeling with the people's psychology. Because the color decoration of industrial products plays a decisive role in the aesthetic appearance of the products, and has the visual performance of regulating the products at the same time, it leads to the balance of the physiological and psychological feelings of the consumers, and satisfies the dual needs of people's material and spiritual life, which also helps the users to produce a good work mood, improve their work efficiency and reduce their visual fatigue. 
When designing the color of products, it should be noted that the color matching should have a "color key" to avoid the excessive approximation of hue, brightness and purity and the equivalence of color area. Besides, there shouldn't be too many hues, and two or three kinds are generally appropriate. Under normal circumstances, a large area of low-purity, and high-brightness color tone predominates, which is decorated with a small area of high-purity color for comparison locally, so that it is easy to achieve a harmonious, rich and eye-catching effect. It should also be pointed out that in the color design, it should pay attention to maintaining a certain adaptation relationship between the product and the use environment, ethnic customs, and geographical and climatic conditions.

1) The cold and warm senses of color

The object can bring people a sense of warmth and coldness through the color on the surface, which is the most common perceptual experience. According to the different temperature feelings it brings to people, the colors can be divided into warm and cool colors. When people see warm colors, they will psychologically have obvious excitement and positive emotions, such as red, orange, and yellow. When they see cold colors, they will psychologically have obvious depression, tranquility, and negative retreat, such as green, blue and other colors.

2). The special sense of color

The spatial sense of color is mainly manifested in its sense of expansion \& contraction and distance. The same volume gives people a different feeling when it is endowed with a different color. In general, warm, light, and bright colors have a sense of expansion, while cool, dark, and dull colors have a sense of contraction, which is the psychological feeling that color brings. The sense of distance indicates the different colors in the same position will bring people a different sense, which is because different colors will cause people to have different feelings about distance. Warm, bright, and solid colors look more prominent and have a sense of movement, such as yellow and orange, etc., while cool, dark, and gray colors look more static and have a sense of backwardness. Therefore, a reasonable application of the sense of distance and expansion \& contraction can make the object obtain an effective sense of layering and space.

3) The weight sense of color

The weight sense of color comes from life experience, which is also related with the sense of space. In general, dark colors make people feel heavy, while light colors make them feel light. Therefore, dark colors give people a solid and heavy feeling, while light colors give them a light and beating feeling. In addition, the weight sense is also related to the texture of the color surface. The colors with a smooth and uniform surface look light, while those with a rough surface look heavy.

4) The soft and hard sense of color

The soft and hard sense of color mainly depends on the brightness and purity. The high-brightness, low-purity and warm colors can make people feel soft, such as light yellow and pink, while the low-brightness, high-purity, and cold colors will make people feel hard, such as dark blue and black. In addition, the psychological effects brought by color are closely related to age, personality, occupation, culture and customs. From the viewpoint of age, the more mature people tend to love the colors that are darker. For example, children love bright colors, such as red, yellow, green, etc., while the elderly prefer black and gray. From the perspective of profession, manual workers love bright colors, while mental workers prefer mature colors such as broken colors, elegant colors, and black colors.

It should be the basic concept for the color design of fire extinguishers to be harmonious with people and home, bright enough to attract attention and easy to be found. There are still a lot of unsatisfactory places in the color design of mobile phones, some of which are with unclear main themes. Although the colors are dazzling, they make people unintelligible; some are ambiguous and the colors make people uncomfortable, causing anxiety or unhappiness; some lack of emotions, and the colors are superficial and indifferent, which seem to keep a good distance from people; some are with improper colors, which are old and conservative, and lack of new ideas and attractiveness, etc. The color design without ideas and emotions can only be a beautiful shell without life and soul no 
matter how high the technique is, which is only a fleeting cloud for consumers and not worth recalling. A successful design makes the design concept perfectly integrated with the color, giving people a visual and psychological balance and allowing people to get the visual enjoyment of beauty. Thus, consumers will have an extraordinary retentive memory and profound impression.

\section{Design schemes}

In this project, my design concept is to give users a new use experience of fire extinguishers, and change the rigid and awkward impression of traditional fire extinguishers in people's minds through transforming the existing fire extinguishers in the market; at the same time, I want to use the creative design of fire extinguishers to convey to modern urbanite a concept of cherishing the present life, hoping that people can cherish their life and the present.

Preliminary sketches and pre-selected schemes

In the preliminary stage of the design, we must try repeatedly with the principle of bold trials and focus on innovative creation, but shouldn't be constrained by existing products. Thus, I made a lot of attempts, and the following is part of them (Figure 2 Figure 3).

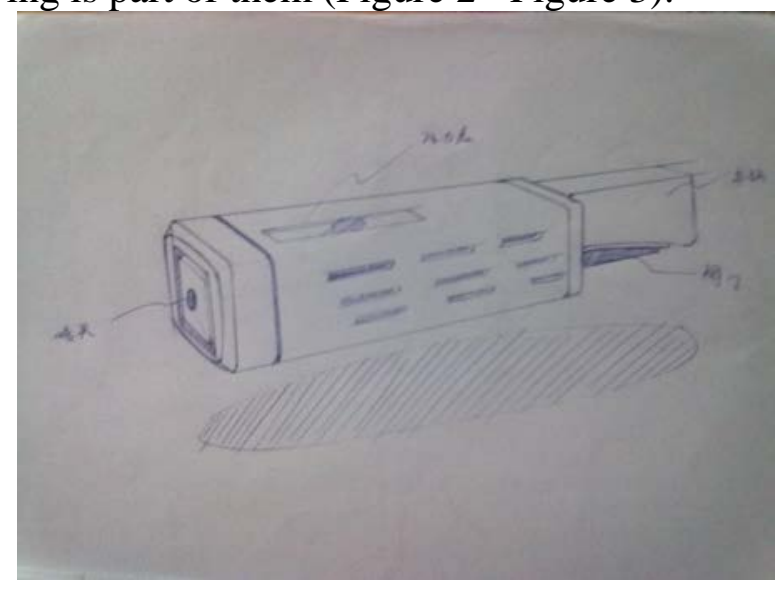

Figure 2 Rough draft 1

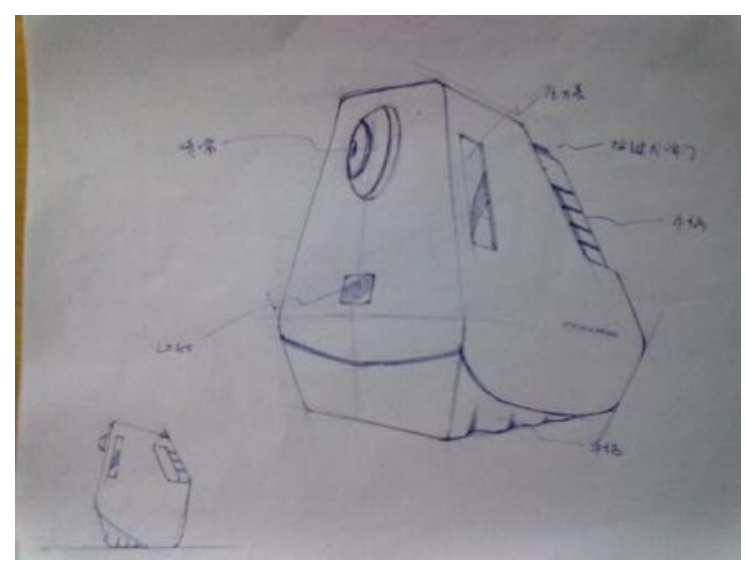

Figure 3 Design schemes

\section{Conclusion}

In the current society with ever-changing technologies, the threat of fire to people has somewhat relieved, but we can't yet relax. Life is so beautiful that it deserves our wholehearted attention and concentrative design. Every bit of life is a precious treasure and I hope to express the theme like that expressed in the movie through this design so as to inspire everyone to love life and feel grateful to life. 


\section{References}

[1] Qing Dong,Fei You,Shi-qiang Hu. Investigation of Fire Protection Status for Nanjing Representative Historical Buildings and Future Management Measures[J]. Procedia Engineering,2014,71.

[2] Kuo-Yi Li. Application of TRIZ in the Innovation Design of the Dry-Powdered Fire Extinguisher Training Device[M].Springer International Publishing:2014-06-15.

[3] Zhuo, Jiang,Yinshui, Liu,Xufeng, Zhao,Wudi, Fang. A portable piston-type water mist fire extinguisher for spacecraft[J]. Proceedings of the Institution of Mechanical Engineers,2015,229(1).

[4] Anonymous. PUTTING A DAMPENER ON FIRE DAMAGE[J]. Civil Engineering : Magazine of the South African Institution of Civil Engineering,2015,23(4).

[5] Peters, William C. Understanding Air Brakes on Fire Apparatus[J]. Fire Engineering,2015.

[6] Burnett, Brandon. Simplifying the Hose Stretch with Strategically Placed Loops[J]. Fire Engineering,2015,168(10).

[7] Vaughn, Allyn J. Know when, where to specify a clean agent system[J]. Consulting - Specifying Engineer,2015.

[8] Anonymous. Advance With Confidence[J]. Fire Engineering,2015,168(12).

[9] Xue Bing Liao,Hai Yan Zhao,Lei Peng,Li Juan Huang. Design of Controlled Fire Extinguisher Filling Pretreatment Equipment of Self-Propelled Artillery[J]. Applied Mechanics and Materials,2014,3082(543).

[10] Ramon Tirschmann,Jens Czäczine,Mathias Hunold. High Volume Production Technology for Corrosive Resistant Long-Fiber-Reinforced Plastic Extinguishers[J]. Materials Science Forum,2015,4082(825).

[11] Crumière P P,Albaladejo R,De Saint Maurice G,Trabold F,Mc Nelis U,Boileau S,Bouaziz H. [Patient associated fire in theatre: Are we ready to prevent and/or manage it? Assessment of the anaesthetist's knowledge in Lorraine.[J]. Annales Francaises d'Anesthesie et de Reanimation,2012.

[12] Cheng-Chan Shih,Richard S. Horng,Shin-Ku Lee,Egidijus R. Vaidogas. Investigation of Lab Fire Prevention Management System of Combining Root Cause Analysis and Analytic Hierarchy Process with Event Tree Analysis[J]. Mathematical Problems in Engineering,2016,2016.

[13] Achmad Mustakim,Firmanto Hadi. Innovated Conceptual Design of Loading Unloading Tool for Livestock at the Port[J]. Journal of Physics: Conference Series,2018,979(1).

[14] Julian F.V. Vincent. Biomimetics in architectural design[J]. Intelligent Buildings International, 2016,8(2). 